\title{
Observation of irregular wave transformation in the surf zone over a gently sloping sandy beach on the French Atlantic coastline
}

\author{
Nadia SÉNÉCHAL*, Hélène DUPUIS, Philippe BONNETON, Hélène HOWA, Rodrigo PEDREROS \\ Department of Geology and Oceanography, UMR CNRS 5805, University of Bordeaux I, 33405 Talence, France
}

Received 16 February 2001; revised and accepted 13 August 2001

\begin{abstract}
The dissipation of the sea-swell frequency band energy (nominally $0.09<f \leq 0.3 \mathrm{~Hz}$ ) and the distribution of low frequency band energy (nominally $0.005 \leq f \leq 0.09 \mathrm{~Hz}$ ) on a transect crossing the surf and swash zones of a fine grained, gently sloping barred beach are investigated with data from a five element synchronous pressure sensor line deployed for $8 \mathrm{~d}$. In this paper, we suggest a rational method to determine the frequency cut-off between the low frequency band and the sea-swell frequency band from the cross-shore evolution of the sea surface elevation energy density spectra. Sea-swell wave heights are depth limited, consistent with previous works whereas low frequency wave heights are independent of the local water depth. In models of surf zone hydrodynamics, wave energy dissipation is often parameterized in terms of $\gamma$, the ratio of the sea-swell significant wave height to the local mean water depth. The observed values of $\gamma$ are well correlated with $\beta / \mathrm{kh}$ (where $\beta$ is the beach slope, h the mean water depth and $\mathrm{k}$ the local wavenumber corresponding to the local centroidal frequency and depth) but the linear regression through the data differs significantly from previous work. Finally, the evolution of the energy distribution in both frequency band indicates the local (not only dependent on the depth) behaviour of two phenomena: the phenomenon of merging shocks and the distribution of low frequency band into two components - principally infragravity motions $(0.005 \leq f<0.05 \mathrm{~Hz})$ or first subharmonic motions $(0.05 \leq f<0.09 \mathrm{~Hz})$. @ 2001 Ifremer/CNRS/IRD/Éditions scientifiques et médicales Elsevier SAS
\end{abstract}

Résumé - Observation de la transformation d'une houle irrégulière en zone de surf le long d'un profil transversal sur une plage sableuse de pente modérée sur la côte atlantique française. La dissipation d'énergie des vagues (fréquences entre 0,09 et $0,3 \mathrm{~Hz}$ ), et la distribution des ondes basses fréquences (fréquences entre 0,005 et $0,09 \mathrm{~Hz}$ ) le long d'un profil transversal ont été étudiées à partir de données acquises à l'aide d'une ligne de cinq capteurs de pression synchronisés, déployés 8 jours consécutifs dans la zone de surf d'une plage sableuse de pente modérée, présentant des systèmes barre-baïne. Nous proposons une méthode rationnelle afin de déterminer la fréquence de coupure entre les basses fréquences et les hautes fréquences (houle et mer du vent) basée sur l'évolution du spectre de densité d'énergie le long du profil transversal. En zone de surf, la hauteur des ondes hautes fréquences (vagues) est contrôlée par la hauteur d'eau locale alors que la hauteur des ondes basses fréquences est indépendante de la hauteur d'eau locale. Dans les modèles hydrodynamiques utilisés en zone de surf, la dissipation d'énergie est souvent paramétrée en terme de $\gamma$, le rapport entre la hauteur significative des vagues et la hauteur d'eau locale. Les données indiquent que $\gamma$ est fortement corrélé à $\beta / \mathrm{kh}$ (où $\beta$ est la pente de la plage, h la hauteur d'eau locale et $\mathrm{k}$ le nombre d'onde associé à la fréquence centroïdale locale). Néanmoins, la régression linéaire obtenue diffère de manière significative de celle obtenue dans de précédentes études. Enfin, le suivi de l'évolution de la distribution de l'énergie au sein des bandes a permis de mettre en évidence deux phénomènes locaux ne dépendant pas uniquement de la profondeur: le phénomène de fusion de fronts

* Correspondence and reprints: fax: +33 55640848.

E-mail address: n.senechal@geocean.u-bordeaux.fr (N. Sénéchal).

(C) 2001 Ifremer/CNRS/IRD/Éditions scientifiques et médicales Elsevier SAS. Tous droits réservés

S0399178401011719/FLA 
d'ondes et la répartition de l'énergie basse fréquence entre deux modes - soit onde infragravitaire, soit sub-harmonique. (C) 2001 Ifremer/CNRS/IRD/Éditions scientifiques et médicales Elsevier SAS

\section{cross-shore approach / wave spectra / wave dissipation / infragravity waves}

\section{profil transversal / spectre de densité d'énergie / dissipation des vagues / ondes basse fréquence}

\section{INTRODUCTION}

An improvement in the knowledge of the mechanisms of wave breaking and energy dissipation on beaches is essential in order to better understand and quantify most coastal sedimentary processes. As waves shoal onto beaches, their amplitude increases, their wavelength decreases and their propagation direction refracts toward shore-normal incidence. These 'linear' propagation effects are readily observed and well understood. Breaking waves are the main driving force of near-shore fluid motions and sediment transport. In the surf zone, turbulence generated by broken waves carries sediment away from the bed and throws it into suspension. The sediment is then available for transport by waves or wave-induced steady currents such as long-shore currents or rip currents Dalrymple, 1979: Falqués et al, 1999) The distribution of the wave heights plays an important role in the determination of water motions. Thus the ratio of the wave height to the water depth $(\gamma)$ is a key parameter in parametric wave models, such as the energy decay model of Battjes and Janssen (1978). Additionally, pronounced non-linear effects in shallow water cause a transformation of wave profiles from initially symmetric, nearly sinusoidal profiles, to asymmetric, pitched forward sawtooth profiles Svendsen et al_ 1978. Elgar and Gwza_ 1985. Norheim et al. 1997). These non-linear effects can also force secondary (infragravity) waves, which are released as free waves 4 ist_ 1992]. These infragravity waves are weakly dissipated in the surf zone and survive to be reflected at the shoreline. Symonds et al. (1982) have subsequently shown that slow oscillations in the wave set-up (associated with slow variations of the breakpoint location of groupy incident swell) can also drive infragravity waves. These long-period waves are believed important to constrain near-shore morphodynamics such as sand bar generation and beach cusp development Bowen and Inman. 1971: Bowen. 1980; Kirby et al 1981: Short and Aagaard. 1993).

One of the main purposes of this study is to report observations of surf characteristics and low frequency oscillations from a set of experiments conducted on an intermediate dissipative beach. Thus, the evolution of the sea surface energy, estimated from the energy density spectra (EDS) of an irregular wave field in the surf zone has been further investigated. In particular, we will characterize the energy evolution of two frequency bands: the sea-swell band (nominally in the band $0.09<f \leq 0.3 \mathrm{~Hz}$ ) and the low frequency band (nominally $0.005<f \leq 0.09 \mathrm{~Hz}$ ), including the 'infragravity' band.

Our study is based on data collected from a cross-shore line of five bottom-mounted pressure transducers on a gently sloping barred beach on the southern part of the French Atlantic coastline. Although data were collected over $8 \mathrm{~d}$, the measurements presented in this study were taken over two high tide cycles, in the presence of low energy incoming swell. Conditions were typical of weak wind sea, as the waves were irregular and relatively weak.

This study suggests a rational method to determine the frequency cut-off between the low frequency band and the sea-swell frequency band. Although the range of wave conditions was limited during the experiment, this study analyses the sea-swell significant wave height dependence on the local mean water depth. Our results are compared with a previous study where sea conditions and study area characteristics were different. In the following, the experiment is first described, and then the observations are analysed and compared to previous works.

\section{MATERIALS AND METHODS}

\subsection{The study area characteristics}

This study is based on data collected during field experiments carried out during $8 \mathrm{~d}$ in May 1998. This fieldwork is part of a French national research pro 
gramme on sandy beach evolution (Programme national d'environnements côtiers). One of the programme's goals is to improve the understanding of the hydrodynamical process generating sediment transport. The data described in this paper were collected at Truc Vert beach, which is situated on the southern part of the French Atlantic coastline approximately $10 \mathrm{~km}$ north of the Cap Ferret spit (igure - $)$. Truc Vert beach is typical of the relatively undisturbed coast extending $100 \mathrm{~km}$ between the Gironde estuary (90 km to the north) and the Arcachon inlet (10 km to the south). This is a low sandy coast, almost $\mathrm{N}-\mathrm{S}$ orientated and bordered by high Aeolian foredunes. The sediment consists primarily of a medium-grained quartz sand with a median particle size around $350 \mu \mathrm{m}$ Lorin and Viguier, 1987). This coast is exposed to almost continuous high energy swell originating mainly from the west-northwest. The wave climate is typically oceanic, with a mean period of $12 \mathrm{~s}$ and a mean significant wave height of $1.55 \mathrm{~m}$ during winter conditions and a mean period of $7 \mathrm{~s}$ and a mean significant wave height of $0.9 \mathrm{~m}$ during summer conditions. The high meso-macro tidal range, approximately $4.5 \mathrm{~m}$ at spring tides, along with the relatively broad intertidal region (around $200 \mathrm{~m}$ ), allows instruments to be deployed and recovered safely at low tide while measurements can be obtained at high tide. The beach exhibits a ridge and runnel system in the dissipative lower intertidal domain, and a steeper beach face (figure 2). Off the beach, crescentic long-shore bars are found, as described in Eroidefond et al_ (1990) and more recently in Michel and Howa (1994). Truc Vert beach is classified as intermediate type 2e (following Masselink and Short_1993).

It is worth noting that this beach is not submitted to any anthropic influence and is outside the influence of the Arcachon inlet and the Gironde estuary. This is evident in the mean horizontal current magnitudes at a bottommounted current meter (fixed $0.6 \mathrm{~m}$ above sea floor) in approximately $9 \mathrm{~m}$ depth: about $0.2 \mathrm{~m} \cdot \mathrm{s}^{-1}$ in the crossshore direction and $0.15 \mathrm{~m} \cdot \mathrm{s}^{-1}$ in the long-shore direction, comparable with tidal currents in the area Lorin and Viguier, 1987).

\subsection{Instrumentation}

Experiments were conducted from 21 May 1998 to 28 May 1998. The measurements were taken over several high tide cycles in the presence of low energy incident swell (significant wave height less than $1.5 \mathrm{~m}$ and mean

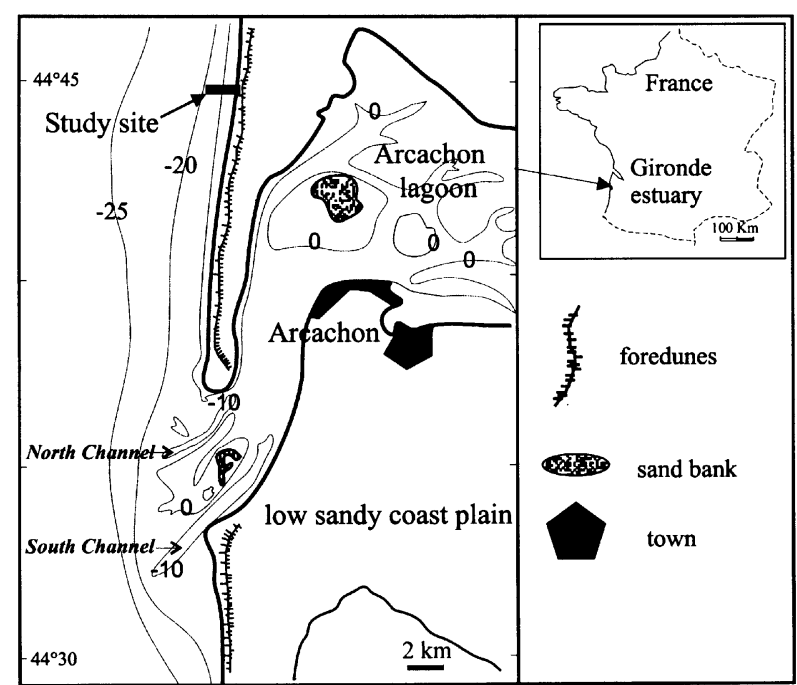

Figure 1. Location of the study area on the southern part of the French Atlantic coastline, outside the influence of the Arcachon inlet and the Gironde estuary. This is a gently sloping barred beach, bordered by high Aeolian dunes.

peak period around $7 \mathrm{~s}$ ). The results presented here focus on measurements taken on 26 May and 28 May 1998.

Three bottom-mounted pressure sensors $(\mathrm{Pa}, \mathrm{Pb}, \mathrm{Pc}$ where $\mathrm{Pc}$ is located the furthest offshore and $\mathrm{Pa}$ the closest onshore) and one bottom-mounted directional wave current meter (DWCM), S1, were deployed in a cross-shore transect. This cross-shore transect was located between two ridge and runnel systems in order to limit the effects of long-shore currents in the rip channel (figure , left). Residual cross-shore currents computed over data acquisition runs at sensor $\mathrm{S} 1(0.5 \mathrm{~m}$ above the bed) were less than $0.09 \mathrm{~m} \cdot \mathrm{s}^{-1}$ for the $2 \mathrm{~d}$, while residual long-shore currents were less than $0.07 \mathrm{~m} \cdot \mathrm{s}^{-1}$. The instruments were situated on the beach face slope in order to be fully immersed at high tide. The tidal ranges on 26 and 28 May were 4.26 and $3.75 \mathrm{~m}$, respectively. A second DWCM was moored $0.5 \mathrm{~m}$ above the bottom at location $\mathrm{S} 2$, offshore of the intertidal ridge in $9 \mathrm{~m}$ water depth at high tide (figure , right). The three pressure sensors are piezoresistive pressure transmitters (Keller PR26W/8369). The sensors measure absolute pressure, with a sensitivity of $16.0 \mathrm{~mA} \cdot \mathrm{bar}^{-1}$ and a precision of $0.6 \%$ (atmospheric pressure has been measured during all the fieldwork to adjust the water depth). The two DWCMs are manufactured by InterOcean System. Models S4DW and S4ADW were deployed at S1 and S2 respectively. 


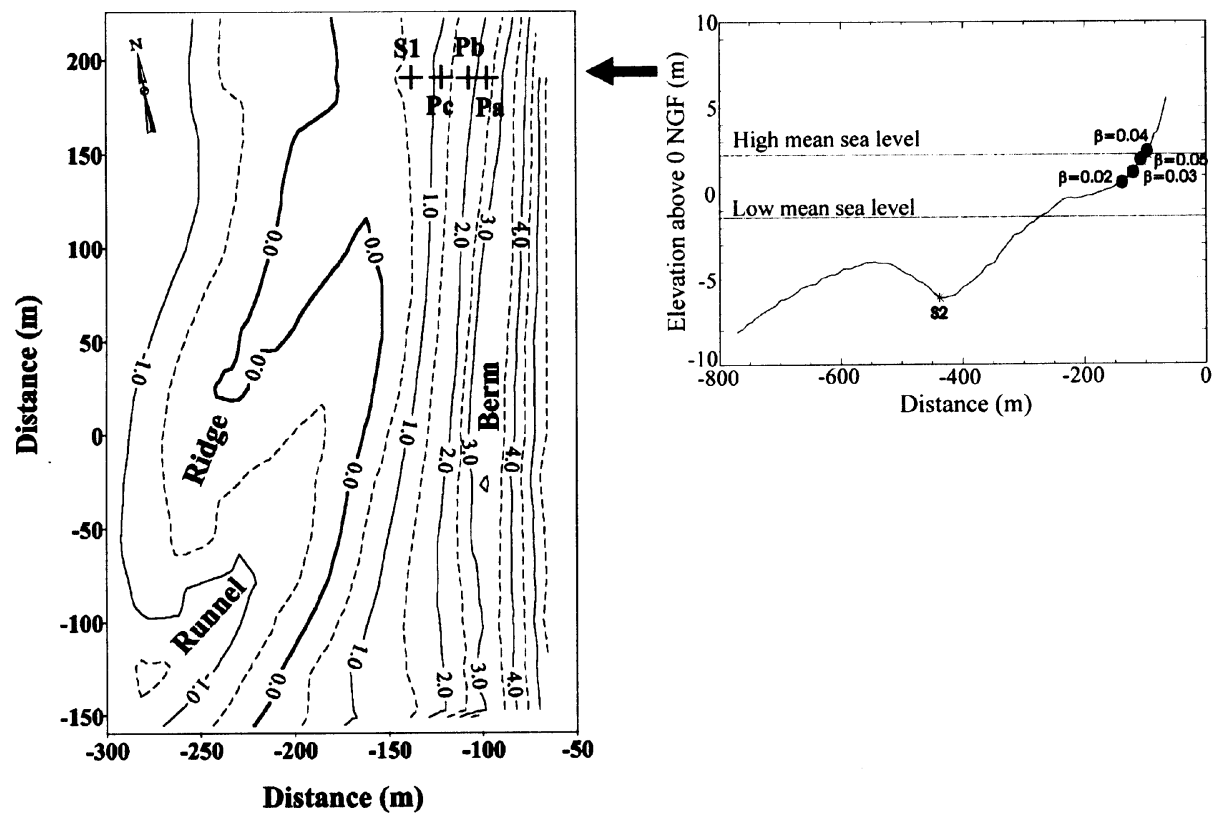

Figure 2. Left: Intertidal morphology of the beach study site with location of the pressure sensors $(\mathrm{Pa}, \mathrm{Pb}$, and $\mathrm{Pc})$ and the S4DW (S1) outside the influence of rip channels. Elevations (in meters) are given above the Normalisation géographique française (the French ordnance datum). Right: cross-shore profile with locations of pressure sensors $(\mathrm{Pa}, \mathrm{Pb}$, and Pc), S4DW (S1) and S4ADW (S2), and approximate beach slopes $\beta$ in $\%$.
Each includes a 70-m high-resolution depth sensor and has a precision of $2 \%$. On the S4 DWCMs, data were acquired continuously at a $2-\mathrm{Hz}$ sample rate throughout the study period. Data from the pressure sensors were relayed via long cables to the top of the beach where the signals were sampled at $3 \mathrm{~Hz}$. During 26 May 1998, three consecutive data runs were acquired, respectively 86,38 and $109 \mathrm{~min}$ long, corresponding to $1 \mathrm{~h}$ before high tide and $3 \mathrm{~h}$ after high tide, and covering water depths between 0.4 and $3.0 \mathrm{~m}$. Data collections were limited to the time during which the sensors were fully immersed. Pressure sensor data were obtained from well outside the surf zone to well within the surf zone. On 28 May 1998, two consecutive data runs (with only a few minutes interruption) were acquired. They were respectively 32 and $97 \mathrm{~min}$ long, corresponding to $2 \mathrm{~h} 30$ after high tide (until Pc was periodically exposed) and covering water depths between 0.2 and $2.0 \mathrm{~m}$. During this day, the pressure sensors were located well inside the surf zone. S1 sensor data were obtained from well outside the surf zone to well within the surf zone for both days. Beach profiles were determined at each low tide using a Leica WLD TC500 theodolite. The precision is $0.2 \%$ for distances and $2.5 \%$ for heights. At each low tide, the heights of the bottom-mounted sensors above the sea floor were also measured (precision: $3 \%$ ) to adjust water depths; thus water depth error is estimated to be less than
$0.1 \mathrm{~m}$. Between two low tides, the beach profile did not change significantly, beach slopes in the surf zone (see below for their determinations) ranged from about 0.02 at $\mathrm{S} 1$ to about 0.05 at $\mathrm{Pb}$ foure 2, right).

\subsection{Methods}

All hydrodynamic data were processed similarly for the two high tide cycles. First, pressure measurements were converted to water elevations. Outside the surf zone, a correction factor as proposed in Horrikawa and Kubota (1988) was applied to account for the pressure field being non-hydrostatic. This correction generates a highfrequency cut-off corresponding to the limit of the sensor sensitivity according to its immersion and the water depth attenuation of the waves. In our case, the high frequency cut-off of $F_{h i}=0.3 \mathrm{~Hz}$ was applied to the whole data set. At frequencies greater than $0.3 \mathrm{~Hz}$, the observed wave energy is relatively small $(<20 \%$ of total energy). A low frequency cut-off of $F_{l o}=0.005 \mathrm{~Hz}$ was also applied to all data. In the surf zone, sea surface elevations were estimated assuming that the pressure field is hydrostatic. Indeed, as shown by Lin and Liu (1998), using a numerical model based on the Reynolds equations, the pressure distribution under spilling breaking waves is almost hydrostatic with a maximum devia 
tion from hydrostatic pressure of only $7 \%$. The maximum deviation occurs under the broken wave front.

The main purpose of this study was to determine the evolution of the sea surface elevation energy, estimated from the energy density spectra (EDS) (i.e. Hegge and Masselink, 1996) on a cross-shore transect in the surf zone in both low and sea-swell frequency bands. The selected data were processed by breaking the entire record into consecutive sections of $600 \mathrm{~s}$ each (periods where tidal variations of the sea surface level are less than $10 \%$ ). Energy estimates were calculated by Fourier transforming overlapping (75\%), Hanning-windowed, and detited 5-min data segments averaged over $10 \mathrm{~min}$.

Then, we used the significant wave height $H_{s}$ (equation 1):

$$
E=\frac{1}{16} \rho g H_{s}^{2}
$$

where $E$ is the energy, $g$ the gravitational acceleration, $\rho$ the water density.

So, in order to analyse separately the two frequency bands, we suggest the following notations: $H_{l o}$ for the significant height associated to the low frequencies (equation 2a), $H_{h i}$ for the significant height associated to the sea-swell frequencies (equation 2b), $E_{l o}$ (proportional to $H_{l o}{ }^{2}$ ) for the mean low frequency energy and $E_{h i}$ (proportional to $H_{h i}{ }^{2}$ ) for the mean high frequency energy.

$$
\begin{aligned}
& H_{l o}=4 *\left[\int_{F_{l o}}^{F_{c}} s(f) d f\right]^{1 / 2} \\
& H_{h i}=4 *\left[\int_{F_{c}}^{F_{h i}} s(f) d f\right]^{1 / 2}
\end{aligned}
$$

where $s(f)$ is the energy density associated with frequency $f$ and $F_{c}$ is the cut-off frequency between the low frequency band and the sea-swell frequency band (see below for its determination).

Observations of the cross-shore evolution of $H_{h i}$ allow us to determine if the sensor is outside or inside the surf zone. Indeed, wave breaking induces a decrease of the sea-swell energy $\left(E_{h i}\right)$. So from a comparison between

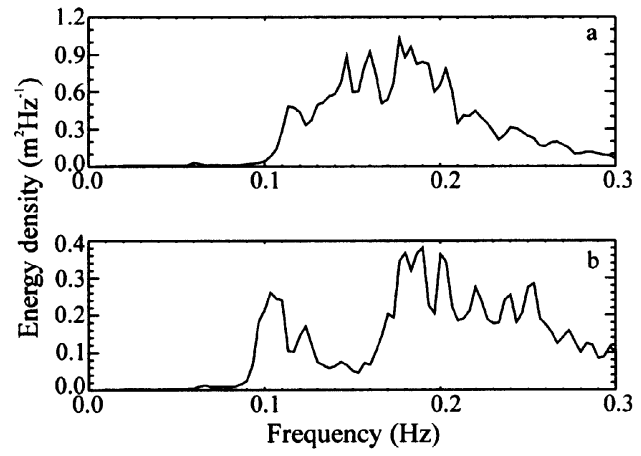

Figure 3. Sea surface elevation energy density spectra (EDS) at bottom-mounted sensor S2 in 9 m water depth (a) 28 May 1998 and (b) 26 May 1998. Significant wave height is $0.8 \mathrm{~m}$ for the 26th and $1.20 \mathrm{~m}$ for the 28th. Energy at low frequencies $(\leq 0.09 \mathrm{~Hz})$ is very low $(<2 \%$ total energy).

one sensor and the others, we can generally determine whether it is or not inside the surf zone.

\section{RESULTS AND DISCUSSION}

\subsection{Sea state conditions as measured offshore}

Figure 3 represents the energy density spectrum (d.o.f. $=42$ ) as measured at station S2 at high tide in about $9 \mathrm{~m}$ water depth. For 28 May 1998 (foure 3d), we distinguish only one broad frequency band in the EDS between 0.1 and $0.2 \mathrm{~Hz}$ corresponding to wind sea energy, significant wave height $H_{s}$ (defined as four times the sea surface elevation standard deviation) at sensor S2 associated to this day is about $1.20 \mathrm{~m}$. Wave crests spread parallel to the coastline. Energy at low frequencies is very low ( $<1 \%$ total energy). For 26 May 1998, we distinguish in Ggure $3 b$ two prevailing frequency bands in the EDS: a first one around $0.1 \mathrm{~Hz}$ corresponding to swell energy and a second much broader one centred between 0.18 and $0.25 \mathrm{~Hz}$ corresponding to wind sea energy. Total significant wave height $H_{s}$ in $8 \mathrm{~m}$ water depth (S2) is about $0.80 \mathrm{~m}$ for this day. Wind sea crests propagate with a weaker angle from the normal of the beach than the swell crests propagate. Energy at low frequencies $(0.005<f \leq 0.09 \mathrm{~Hz})$ is very low $(<2 \%$ total energy at S2). 


\subsection{Frequency cut-off between low and high frequencies}

At first, the main purpose is to segregate properly the 'total energy spectra' into two frequency bands representative of low frequencies and sea-swell frequencies (including pure wind-sea) and then to analyse their respective spectral evolutions on a cross-shore transect. Actually there is no general agreement about the definition of the frequency cut-off between high and low frequency bands (including infragravity band) and its determination varies from an author to the other. For example, Roelvink and Stive (1989) suggest taking the limit at $0.5 F_{p}$ where $F_{p}$ is the main spectral offshore peak, assumed to be invariant as the waves shoal in the cross-shore direction. In our case, since the offshore conditions are typical of weak wind sea with a relative broad band EDS and no real frequency peak (or at least greatly variable in short time) and since the wave period density function is deeply modified along the cross-shore transect Sénéchal et al. 2001) such a criterion is not suitable. Herbers et al. (1995) took a constant 0.04-Hz cut-off frequency whatever the offshore swell energy is, to avoid contamination of the infragravity band estimates by more energetic swell. Finally Holland and Holman (1999) as well as Rawhenheimer et al (1996) took a constant $0.05-\mathrm{Hz}$ cut-off frequency whereas frequency peaks and sea surface elevation energy density spectra were very different (frequency peaks ranged from 0.06 to about $0.14 \mathrm{~Hz}$ ). This underlines the doubt in the determination of this high-frequency cut-off. In our point of view, this threshold is like a 'climatological' value, only justified in the presence of a spectral gap around this cut-off. But in our data, there is no systematic evidence for such a spectral gap, especially in the surf zone. Instead, we determine the cut-off by using the observations of the evolution of the EDS along a cross-shore transect for each 10-min period. We calculate the ratio between the EDS at sensor $\mathrm{S} 2$ situated off the beach (EDS $\left.{ }_{\text {off }}\right)$ and the EDS at sensors situated in the intertidal zone $\left(\mathrm{EDS}_{\mathrm{int}}\right)$. We observed for each high tide cycle, a frequency cut-off under which the ratio $\left(\mathrm{EDS}_{\text {off }} / \mathrm{EDS}_{\text {int }}\right)$ is of the order of $10^{-1}$ whereas above this frequency threshold the ratio ranges from 1 to 10 , thus with a pronounced variation of a factor 10 to 100 around the cut-off frequency. It is noteworthy that the transition between the two domains is very abrupt and was observed in all runs. Figure 4 shows the ratio $\mathrm{EDS}_{\text {off }} / \mathrm{EDS}_{\text {int }}$ for a 10 -min period during the 28 May experiment. The two domains are clearly distin-

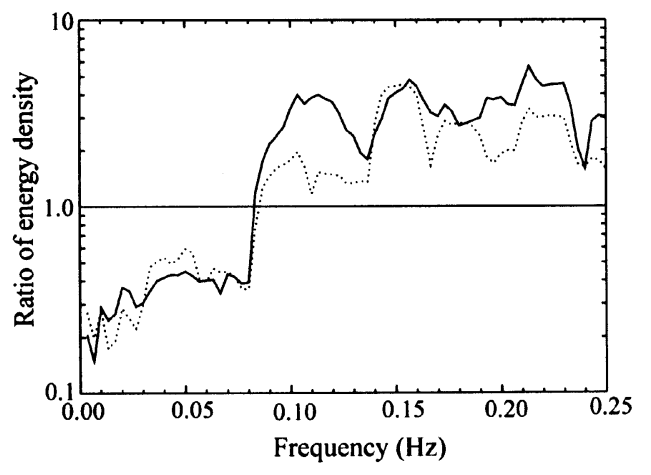

Figure 4. Example of ratio $\mathrm{EDS}_{\text {off }} / \mathrm{EDS}_{\text {int }}$ between energy density computed at sensor S2 (in $8 \mathrm{~m}$ water depth) and sensors $\mathrm{Pa}$ (solid line) and $\mathrm{Pb}$ (dashed line). We clearly distinguish two areas (ratio $>1$ and ratio $<1$ ) delimited by a very abrupt transition. This pronounced threshold seems to be a good criterion which provides an objective determination of the cut-off frequency between the sea-swell frequency band and the infragravity band, here $F_{c}=0.082 \mathrm{~Hz}$ (standard deviation less than $0.01 \mathrm{~Hz}$ for all the data set).

guished. The first domain (ratio $<1$ ) is mainly due to the weak infragravity frequency band energy $(<2 \%$ total energy, see (Goure 3) at the offshore location, but also to the increase of low frequency energy (by a factor 5 to 7 ) in the intertidal zone. The second domain (ratio $>1$ ) essentially corresponds to the loss of energy associated with wave breaking. This frequency cut-off has very slight variations $(<10 \%)$ for each 10 -min period of our data set. For 26 and 28 May 1998, this frequency cut-off found to be the same is $F_{c}=0.09 \mathrm{~Hz}$ (with a standard deviation of $0.01 \mathrm{~Hz}$ for the 28th and $0.003 \mathrm{~Hz}$ for the 26th). So the ratio $\operatorname{EDS}_{\text {off }} / \mathrm{EDS}_{\text {int }}$ seems to be a good criterion which provides an objective determination of the cut-off frequency in presence of a very abrupt transition between the two frequency bands. This allows us to discriminate properly two frequency bands: a low frequency band and a sea-swell band. In the following, the energy density spectrum evolution will be analysed in both low and high frequency bands.

\subsection{Significant wave height evolution}

Considering now the evolution of the significant wave height at sea-swell frequencies in the surf zone, the result is consistent with previous laboratory observations Stive, 1984: Svendsen, 1984) and previous field experiments Wright et al. 1982; Thornton and Guza. 1982). These studies suggested that the significant heights $\left(H_{s}\right)$ 


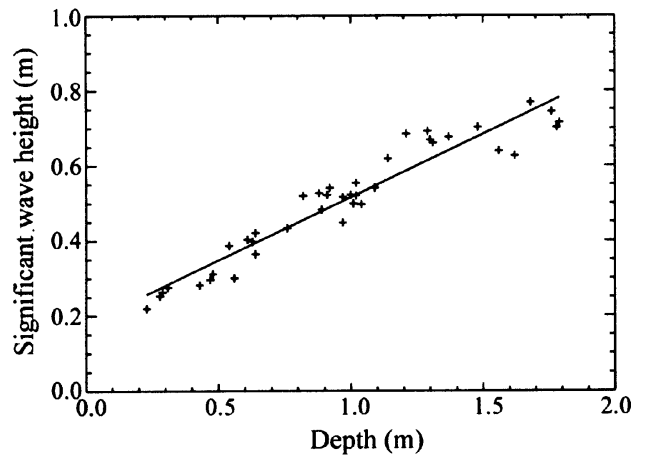

Figure 5. Significant sea-swell wave height $H_{h i}$ (defined as four times the sea surface elevation standard deviation in the sea-swell frequency band) versus depth (h) for all the 10-min periods during the two survey runs when the sensors are located in the surf zone (cross). The least square linear fit (solid line) is $H_{h i}=0.18+0.34 \mathrm{~h}$, correlation coefficient $=0.96$.

of broken waves in the surf zone are depth (h) limited (i.e. Ggure 5). The least square linear fit (correlation coefficient $=0.96$ ) is:

$$
H_{h i}=0.18+0.34 \mathrm{~h}
$$

Many models in the surf zone parameterize wave energy dissipation in terms of semi-empirical $\gamma$ values defined as the ratio of the significant wave height to the local depth. Random wave heights can be considered as limited by the local water depth (i.e. approximately independent of the offshore wave height). In our case, the observed values of $\gamma$ increase from 0.38 after breaking to 0.95 well inside the inner surf zone (figure ). This is consistent neither with the result of Andersen and Fredsoe (1983) who suggested that this value decreases from the value of about 0.8 at the initiation of wave-breaking to become almost constant at about 0.5 in the inner zone, nor with other previous studies, which suggested that this value is constant Thornton and Guza, 1982, 1983. But it is qualitatively consistent with the study of Raubenheimer et al_(1996) in which observed values of $\gamma$ ranged from 0.20 to 1.40 . Figure 6 represents our $\gamma$ values computed from the 26 and the 28 May data (cross symbol) versus normalized beach slopes $\beta / \mathrm{kh}$ (where $\beta$ is the beach slope estimated from the observed profiles as the difference in vertical elevation over a distance equal to shallow water wavelength at the local sea-swell centroidal frequency, $\mathrm{k}$ the local wavenumber corresponding to the local centroidal frequency and depth and $h$ the local depth). The least square linear fit between $\gamma$ and $\beta / \mathrm{kh}$ is displayed by a solid line in figure 6 As suggested by Raubenheimer et al

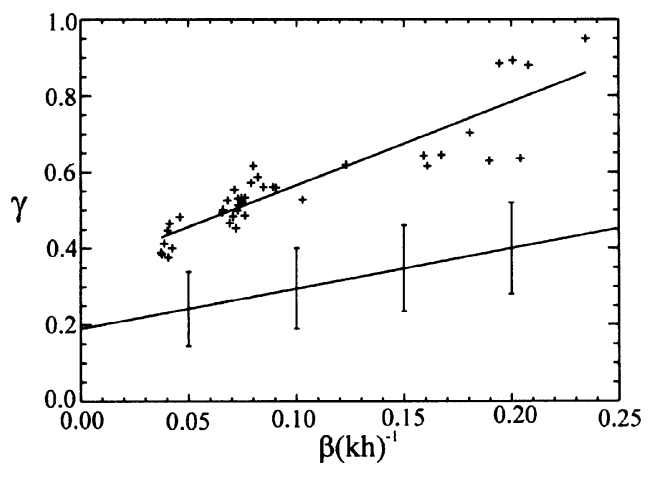

Figure 6. Ratio $\gamma$ of the significant wave height $H_{h i}$ to the local depth $\mathrm{h}$, versus normalized beach slope, $\beta / \mathrm{kh}$, for all the 10 -min periods during the two survey runs when the sensors are located in the surf zone (cross). The least square linear fit (solid line) is $\gamma=0.35+2.18 \beta / \mathrm{kh}$, correlation coefficient $=0.90$. The solid line with error bars is the trend suggested by Raubenheimer and al. (1996 for $0 \leq \beta / \mathrm{kh} \leq 0.25$ (trend was established for $0 \leq \beta / \mathrm{kh} \leq 1$ ).

1996) the $\gamma$ values are well correlated with $\beta / \mathrm{kh}$. The least squares linear fit to the data of Goure is (correlation coefficient $=0.9$ ):

$$
\gamma=0.35+2.18(\beta / \mathrm{kh})
$$

The high correlation coefficient between $\gamma$ and $\beta / \mathrm{kh}$, where $\mathrm{k}$ is the wavenumber associated with the local sea-swell frequency, seems to be consistent with the assumption that the local significant wave height in the surf zone is approximately independent of both the offshore wave height and offshore conditions (foure 3) as previously observed by Raubenheimer et al (1996). Likewise, regarding the beach slope, it appears that it is not necessary to consider the local beach slope and that considering a global beach slope (estimated from the observed profiles as the difference elevation over a distance equal to shallow water wavelength at a frequency cut-off) is sufficient. Nevertheless, even if the local beach slopes are similar to those of Raubenheimen et_al_(1996): between 0.02 and 0.05 here, and between 0.01 to 0.09 in their study, our data do not follow their regression, denoted by the solid line with error bars in Goure 6 . Our data are systematically greater than their values and lie outside their error bars. This effect would be even greater if the same frequency cut-off $F_{l o}$ were used (i.e. if we use the frequency cut-off of 0.05 instead of $0.09 \mathrm{~Hz}$ ). Our results confirm the strong correlation between $\gamma$ and $\beta / \mathrm{kh}$, but show that a simple universal parameterization based on a linear relation between $\gamma$ and $\beta / \mathrm{kh}$ is not valid. Indeed, from analytical models for wave 
dissipation in the inner surf zone, such as those of Stive 1984) or Bonneton 2001 it can be shown that the relation between $\gamma$ and $\beta / \mathrm{kh}$ is not linear and depends also on $H_{b} / \mathrm{h}_{b}$ and $\beta / \mathrm{k}_{b} \mathrm{~h}_{b}$, where $b$ indicates the values at the breakpoint location. This last point like the validity of a simple linear relation is at the present time further investigated with data collected at the same beach in March 2000.

\subsection{Low frequency phenomena}

Considering now the low frequency band, the plot of absolute $H_{\text {lo }}$ (foure $7 d$ ) shows a relative constancy of surf beat heights at outer $(\mathrm{S} 1, \mathrm{Pc})$ and inner $(\mathrm{Pb}, \mathrm{Pa})$ stations. This is consistent with the result of Wright et al. (1982) and also with the recent result of Ruessink (1998] when his entire measurement transect experienced surf zone conditions (wave heights about 2-3 m). Nevertheless, as Wright et_al_(1982) suggested, this effect may be the result of the somewhat arbitrary definition of low frequency motion as consisting of all periods greater than $11 \mathrm{~s}$ in our case (greater than $30 \mathrm{~s}$ in the case of Wright et al. (1982) and greater than $25 \mathrm{~s}$ in the case of Ruessink (1998)

A shoreward increase in relative height of the surf beat is strongly evident from the curve of the ratio $H_{l o}(\mathrm{~T}>11 \mathrm{~s}) / H_{h i}(\mathrm{~T}<11 \mathrm{~s})$ which rises from the vicinity of 0.4 at the outer station (S1) to over 1.2 at the inner station (Pa) (fgure 7b). Wright et_al_(1982) also observed such an increase of the relative height. They noted a
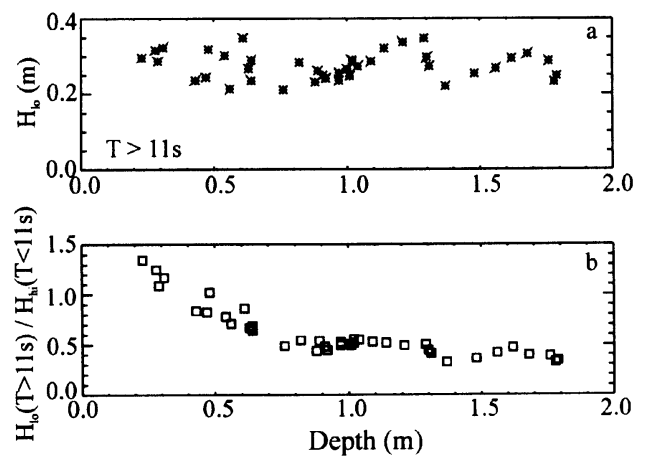

Figure 7. (a) Absolute $H_{l o}(T>11 \mathrm{~s})$ at different depths across the surf zone. (b) Relative $H_{l o}(T>11 \mathrm{~s})$ expressed as a ratio relative to the significant sea-swell wave height $(T<11 \mathrm{~s})$. shoreward increase from the vicinity of 1 at the outer station to over 2 at the inner station. Note that this discrepancy in the values is certainly due to the fact that all their sensors were deployed across the inner $150 \mathrm{~m}$ of a wide surf zone (about $500 \mathrm{~m}$ ) with high incident wave energy (wave height about 3-4 m) whereas our data have been collected along a short surf zone (about $150 \mathrm{~m}$ ) with low incident wind sea.

Several mechanisms behind the generation of low frequency waves have been proposed. Particularly, it has been shown that resonant non-linear interactions between freely propagating waves excite forced waves Hasselmann. 1962: Elgar and Guza, 1985: Herbers et al. 1995 and that non-linear triad interactions are a plausible mechanism for the transfers of energy to lower frequencies in shallow water (Elgar and Guza. 1985. Herbers et al. 1995.

In the following, the structure of the low frequency band energy density spectrum in the surf zone will be further investigated for 28 May to further characterize low frequency phenomena. In particular, emphasis will be placed on the evolution of the energy distribution inside the low frequency band. The high frequency band will also be displayed as a reference.

Figure 8 represents the averaged normalized energy density spectra (NEDS) as measured in the surf zone. EDS in the low frequency band has been normalized by the total energy contained in the low frequency band and

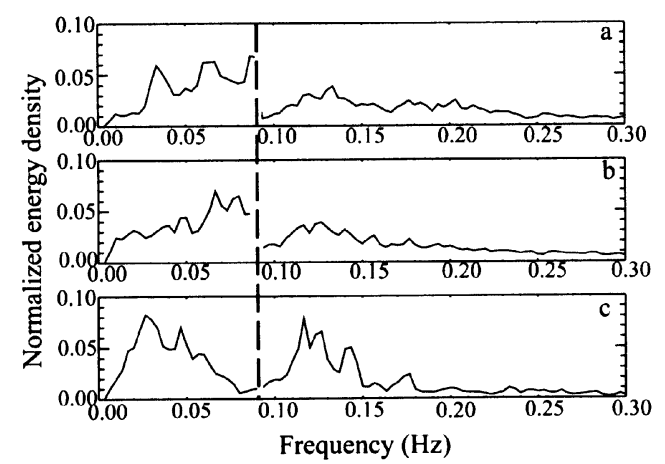

Figure 8. In each frequency band averaged normalized energy density spectra in the surf zone: (a) at sensor S1 for depths ranging 1.79 to $1.26 \mathrm{~m}$; (b) at sensor $\mathrm{Pc}$ and $\mathrm{Pb}$ for depths ranging 1.30 to $0.14 \mathrm{~m}$; (c) at sensor Pa for depth less than $0.3 \mathrm{~m}$. 
EDS in the high frequency band has been normalized by the total energy contained in the high frequency band so that:

$$
\begin{gathered}
F_{l o} \leq f<F_{c}, N E D S(f)=\frac{s(f)}{\sum_{F_{l o}} s(f)} \text { and } \sum_{F_{l o}}^{F_{c}} N E D S(f)=1 \\
F_{c} \leq f<F_{h i}, N E D S(f)=\frac{s(f)}{\sum_{F_{c}} s(f)} \text { and } \sum_{F_{c}}^{F_{h i}} N E D S(f)=1
\end{gathered}
$$

where $s(f)$ is the energy density associated with frequency $f$.

The long dashed line indicates the limit between the two frequency bands. Figure $8 a$ has been obtained by averaging ten consecutive NEDS as measured at sensor S1 (while in the surf zone) during falling tide condition and covering mean water depths from 1.79 to $1.26 \mathrm{~m}$. Eigurd 86 has been computed by averaging eleven consecutive NEDS as measured at sensor $\mathrm{Pc}$ and ten consecutive NEDS as measured at sensor $\mathrm{Pb}$ during falling tide condition and covering water depths from 1.30 to $0.14 \mathrm{~m}$. Figure $8 d$ has been established by averaging four consecutive NEDS as measured at sensor Pa (water depth less than $0.3 \mathrm{~m}$ ). We clearly distinguish the strong modification of the energy distribution in each frequency band. Indeed, in the low frequency band, we clearly observe the down-shifting of the EDS between Ggure $8 \mathrm{~d}$ and $\mathrm{C}$. The mean centroidal frequency computed in the low frequency band abruptly decreases from $0.058 \mathrm{~Hz}$ in fourd Ga(standard deviation is 0.005 ) and $0055 \mathrm{~Hz}$ in fioure $8 \mathrm{~b}$ (standard deviation is 0.005 ) to $0.041 \mathrm{~Hz}$ in figure 8 (standard deviation is 0.002). This phenomenon occurs on a very short distance (about $20 \mathrm{~m}$ ) and is not only due to the decrease of the water depth figure $8 b$ includes data covering water depths from 1.30 to $0.14 \mathrm{~m}$ ) but is a local phenomenon. Indeed, considering only NEDS for sensor $\mathrm{Pb}$, when it is in less than $0.3 \mathrm{~m}$ water depth (three consecutive NEDS), we find a mean centroidal frequency of $0.053 \mathrm{~Hz}$ with a standard deviation of 0.004 (considering NEDS for water depth less than $0.5 \mathrm{~m}$ (six consecutive NEDS) leads to a mean centroidal frequency of $0.053 \mathrm{~Hz}$ and a standard deviation around $0.05 \mathrm{~Hz}$ ). Until sensor $\mathrm{Pb}$, only $36 \%$ of the low frequency energy (standard deviation is $10 \%$ for the 31 NEDS being considered and covering water depths from 1.79 to $0.14 \mathrm{~m}$ ) is contained in the infragravity band (nominally
$0.005 \leq f<0.05 \mathrm{~Hz}$ ) whereas at sensor $\mathrm{Pa}, 67 \%$ of the low frequency energy (standard deviation is $5 \%$ for the four NEDS being considered) is contained in the infragravity band. It appears that until sensor $\mathrm{Pb}$, the low frequency energy is dominated by the first subharmonic frequency band (nominally $0.05 \leq f<0.09 \mathrm{~Hz}$ ), even when $\mathrm{Pb}$ is situated in the swash zone. This is not consistent with the result of Guza et_al_(1984) who showed that motions at surf beat frequencies (defined as $f<0.05 \mathrm{~Hz}$ ) dominate the swash spectrum on dissipative beaches. Nevertheless at sensor Pa, also situated in the swash zone, low frequency energy is dominated by infragravity waves, consistent in this case with Guza et al 1984). It looks as if the first subharmonics were not transmitted between $\mathrm{Pb}$ and $\mathrm{Pa}$ and the infragravity band would be strongly amplified or as if the first subharmonics were transferred to infragravity motions between sensor $\mathrm{Pb}$ and $\mathrm{Pa}$. The reason for this is not yet understood. It may be the effect of the local morphology of the beach. Further investigations are required to understand this phenomenon.

Bound long waves (Hasselmann, 1962:_Longuet-Higgins and Stewart, 1962) could partly explain the infragravity band energy. Indeed, we clearly observed incident wave groups at the offshore sensor S2 (fgure 9d). The existence of these wave groups gives rise, through wave-wave interaction, to second order waves, which may then be released in the surf zone. The incident-wave time series envelope $A(t)$ has been computed in order to check the wave envelope energy density spectrum. Indeed, we suppose that most of the bound long wave energy will be contained in the same frequency band as is the wave envelope energy. $A(t)$ is derived from the time series $\eta(t)$ at sensor S2 (in about $9 \mathrm{~m}$ water depth) through three simple operations. The time series is first linearly detrended to exclude effects of the rising and the falling of the tide and then high-pass filtered with a cut-off frequency of $0.05 \mathrm{~Hz}$ (20-s period). The high-pass filtered signal is called 'basic signal'. The 'basic signal' is also low-pass filtered with a high frequency cut-off to exclude high-frequency signals, either artificial (e.g. electrical noise) or high-frequency capillary waves. The filtering was accomplished in the frequency domain. The highfrequency filter cut-off was set at $0.3 \mathrm{~Hz}$. Zero crossings were localized from the low-pass filtered 'basic signal'. Second, we find $|\eta(t)|$ to introduce envelope-related variance to the series and we determine the maxima between two successive zero crossings. The final step in 


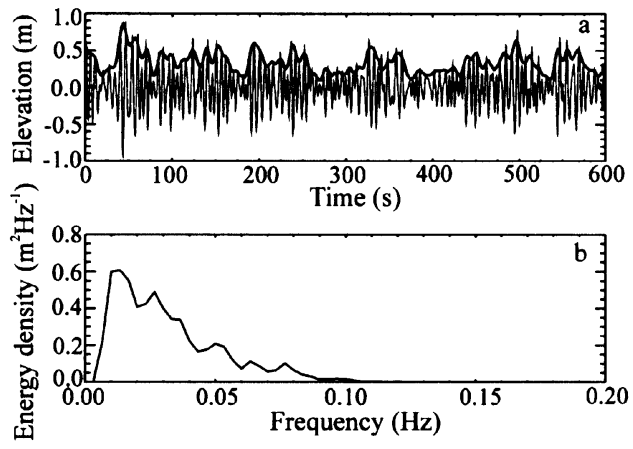

Figure 9. (a) Observed wave group in the time series at sensor S2 (about $9 \mathrm{~m}$ water depth) and computed incident-wave time series envelope (thick solid line), (b) EDS of the envelope, $90 \%$ of the energy is in the $0.005-0.05-\mathrm{Hz}$ frequency band.

finding $\mathrm{A}(\mathrm{t})$ is to compute a linear interpolation between each maximum and smoothing the obtained signal ffourd 2a). Ninety percent of the energy of the incident time series envelope is in the infragravity band energy and we distinguish no significant frequency peak (foure 9b). So, we can suppose that this phenomenon is one of the phenomena generating infragravity energy in our case. Nevertheless the structure of the envelope energy density spectrum clearly differs from those found at sensors S1, $\mathrm{Pc}$ and $\mathrm{Pb}$ (see figure $8 \mathrm{a}$ and $\mathrm{b}$ ) and this theory cannot support the abrupt modification observed at sensor $\mathrm{Pa}$.

Nevertheless, even if the long-shore effects are limited, we can suppose that the infragravity band may have been weakly contaminated. Following a long-shore approach, Holland and Holman (1999) showed clear partitions of infragravity band energy levels associated with leaky waves, edge wave modes, bound waves and non-gravity waves.

Another possible mechanism for low frequency wave generation in the surf zone is the merging of bores as illustrated in Ggure 10 Lsee also Bonneton and Dupuis 2001). This figure shows synchronized time series at sensors (a) Pc, (b) Pb and (c) Pa on the 28 May. Sénéchad te al_(2001, focusing on a 30-min section centred on the high tide on the 28th have shown that this phenomenon was particularly significant for this data set. This led to a significant modification of the wave period distribution, as measured by a down-crossing method but also to the associated down-shifting of the EDS in the high frequency band. In particular, the wave period distribution shows wave periods equal or greater than twice the

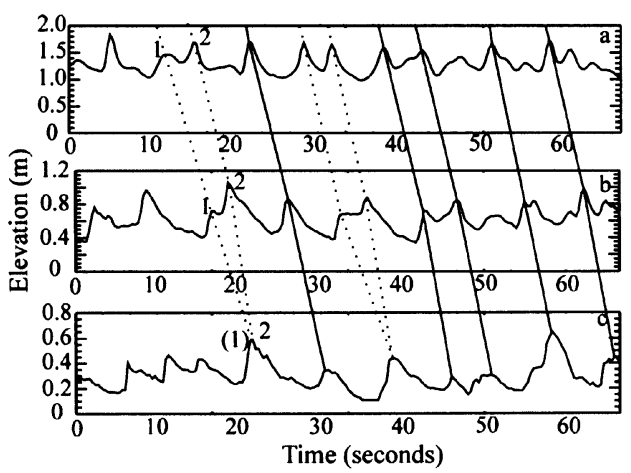

Figure 10. Synchronized time series (a) at sensor $\mathrm{Pc}$, (b) at sensor $\mathrm{Pb}$ and (c) at sensor Pa. Dotted lines indicate the formation of merging shocks.

offshore mean period, which can lead to weak energy contamination in our low frequency band.

Figure 8 clearly shows the down-shifting of the energy density in the high frequency band. The mean centroidal frequency computed in the high frequency band slightly decreases from $0.176 \mathrm{~Hz}$ in foure $8 d$ (standard deviation is 0.006 ) to $0.169 \mathrm{~Hz}$ in foure $8 \mathrm{~b}$ (standard deviation is 0.007 ) and then more abruptly to $0.152 \mathrm{~Hz}$ in foure $8 \mathrm{~d}$ (standard deviation is 0.002). This phenomenon, which mainly depends on the local water depth appears to be locally stressed at sensor Pa. Indeed, considering only NEDS for sensor $\mathrm{Pb}$, when it is in less than $0.3 \mathrm{~m}$ water depth leads to a mean centroidal frequency of $0.16 \mathrm{~Hz}$ with a standard deviation of $0.004 \mathrm{~Hz}$.

The abrupt modification of the low frequency energy distribution and the stressed decrease of the high frequency mean centroidal frequency at sensor Pa are not fully understood and should be further investigated.

\section{CONCLUSION}

The evolution of the EDS on a cross-shore transect allowed us to separate the total wave energy into two frequency bands: a sea-swell band $(0.09<f \leq 0.3 \mathrm{~Hz})$, characterized by the ratio $\mathrm{EDS}_{\text {off }} / \mathrm{EDS}_{\text {int }}$ (the ratio of the energy density offshore, in about $8 \mathrm{~m}$ water depth, and within the intertidal zone) greater than 1 and a low frequency band $(0.005 \leq f \leq 0.09 \mathrm{~Hz})$, characterized by the ratio less than 1. The ratio $\mathrm{EDS}_{\text {off }} / \mathrm{EDS}_{\text {int }}$ seems to be a good criterion to provide an objective determination of 
the frequency cut-off. Indeed, the transition between the two domains is very abrupt (fgure 4).

The sea-swell energy $H_{h i}$ is depth limited (foure - 5), consistent with previous laboratory observations and field experiments. The observed ratio $\gamma\left(H_{h i} / \mathrm{h}\right)$ is well correlated with $\beta / \mathrm{kh}$ (Goure 6 ) but the least squares linear fit diverges from the results of Rawhenheimer et_al_(1996) and our data are significantly outside their error bars. This shows that the parameterization based on a linear relation between $\gamma$ and $\beta / \mathrm{kh}$ is not suitable.

Low frequency energy $E_{l o}$ is independent of the mean local depth (figure $7 d$ ). In the upper surf zone, there is more energy in the infragravity wave band than in the sea-swell band (figure 7 b) consistent with previous results obtained on a high-energy dissipative surf zone Wrigh et al. 1982).

The evolution of the energy distribution in the low frequency band (figure ) clearly shows the local behaviour of two phenomena. First until sensor $\mathrm{Pb}$, the low frequency energy is primarily contained in the subharmonic band (nominally $0.05 \leq f<0.09 \mathrm{~Hz}$ ), even when the sensor is in the swash zone (foure $8 a, b$ ) and then it is primarily contained in the infragravity band (nominally $0.005 \leq f<0.05 \mathrm{~Hz}$ ), which can be only partly explained by the bound long wave theory (foure $)$. Second the phenomenon of merging shocks (fgure 1 d ) is also stressed at sensor $\mathrm{Pa}$ (figure 8c). It is associated with a decrease of the high frequency mean centroidal frequency. The reasons for this high frequency mean centroidal frequency stressed decrease and this abrupt low frequency energy distribution modification, which occurs at the same location, are not well understood, although we believe that it may be due to the local morphology of the beach.

\section{Acknowledgements}

This study was performed within the framework of the Programme national d'environnements côtiers, project 'Hydrodynamique sédimentaire en zone côtière', sponsored by CNRS/INSU. Partial support was also received from the European Community under MAST contract No. MAS3-CT-0106. We would like to thank Dr F. Levoy, Prof. J.P. Barusseau, Mr A. de Resseguier and Mr G. Oggian for their contributions.

\section{REFERENCES}

Andersen, O.H., Fredsoe, J., 1983. Transport of suspended sediment along the coast, Progress Report No. 59, Inst. Of Hydrodynamics and Hydraulic Engineering, ISVA, Techn. Univ. of Denmark, pp. 33-46.

Battjes, J.A., Janssen, J.P.F.M., 1978. Energy loss and set-up due to breaking in random waves, Proc. of the 16th International Conference on Coastal Engineering, Am. Soc. of Civ. Eng., New York, pp. 569-587.

Bonneton, P., 2001. Note sur la propagation des vagues en zone de surf interne. C.R. Acad. Sci. Paris, série IIb 329, 27-33.

Bonneton, P., Dupuis, H., 2001. Transformation of irregular wave in the inner surf zone. Proc. 27th Int. Conf. on Coastal Eng. 1, 745-754.

Bowen, A.J., 1980. Simple models of nearshore sedimentation; beach profiles and longshore bars, Geological Survey of Canada, pp. 1-11.

Bowen, A.J., Inman, D.L., 1971. Edge waves and crescentic bars. J. Geophys. Res. 94, 18023-18030.

Dalrymple, R.A., 1979. Rip currents and theirs causes, Proc. of the 16th Conference on Coastal Engineering, Am. Soc. Of Civ. Eng., New York, pp. 1414-1427.

Elgar, S., Guza, R.T., 1985. Observations of bispectra of shoaling surface gravity waves. J. Fluid Mech. 161, 425-448.

Falqués, A., Montoto, A., Vila, O., 1999. A note on hydrodynamic instabilities and horizontal circulation in the surf zone. J. Geophys. Res. 104-C9, 20605-20615.

Froidefond, J.M., Gallissaires, J.M., Prud'homme, R., 1990. Spatial variation in sinusoidal wave energy on a crescentic nearshore bar; application to the Cap Ferret coast, France. J. Coastal Res. 6-4, 927-942.

Guza, R.T., Thornton, E.B., Holman, R.A., 1984. Swash on steep and shallow beaches. Coastal Eng., 708-723.

Hasselmann, K., 1962. On the non-linear energy transfer in gravity wave spectrum I. J. Fluid Mech. 12, 481-500.

Hegge, B.J., Masselink, G., 1996. Spectral analysis of geomorphic time series: auto-spectrum. Earth Surface Processes Landforms 21, 1021-1040.

Herbers, T.H.C., Elgar, S., Guza, R.T., 1995. Generation and propagation of infragravity waves. J. Geophys. Res. 100, 24863-24872.

Holland, K.T., Holman, R.A., 1999. Wavenumber-frequency structure of infragravity swash motions. J. Geophys. Res. 104, 13479-13488.

Horrikawa, K., Kubota, S., 1988. Nearshore dynamics and coastal processes, Part V Chap. 2, pp. 386-406.

Kirby, J.T., Dalrymple, R.A., Liu, L.F., 1981. Modification of edge waves by barred-beach topography. Coast. Eng. 5, 35-45.

Lin, P., Liu, P.L.F., 1998. A numerical study of breaking waves in the surf zone. J. Fluid Mech. 359, 239-264.

List, J.H., 1992. A model for the generation of two-dimensional surf beat. J. Geophys. Res. 97-C7, 5623-5635.

Longuet-Higgins, M.S., Stewart, R.W., 1962. Radiation stress and mass transport in surface gravity waves with applications to 'surf beats. J. Fluid Mech. 13, 481-504. 
Lorin, J., Viguier, J., 1987. Hydrosedimentary conditions and present evolution of Aquitaine Coast. Bull. Inst. Geol. Bassin Aquitaine 41.

Masselink, G., Short, A.D., 1993. The effect of tide range on beach morphodynamics: a conceptual model. J. Coastal Res. 9, 785-800.

Michel, D., Howa, H., 1994. Morphological evolution of a littoral sandy bank, modelisation of its dynamics. Ann. Geophys. EUG Grenoble II-12 C240.

Norheim, C.A., Herbers, T.H., Elgar, S., 1997. Nonlinear evolution of surface wave spectra on a beach. J. Phys. Oceanogr. 28, 1534-1551.

Raubenheimer, B., Guza, R.T., Elgar, S., 1996. Wave transformation across the inner surf zone. J. Geophys. Res. 101, 25589-25597.

Roelvink, J.A., Stive, M.J.F., 1989. Bar-generating cross-shore flow mechanisms on a Beach. J. Geophys. Res. 94, 4785-4800.

Ruessink, B.G., 1998. Bound and free infragravity waves in the nearshore zone under breaking and nonbreaking conditions. J. Geophys. Res. 103-C6, 12795-12805.

Sénéchal, N., Bonneton, P., Dupuis, H., 2001. Field observations of irregular wave transformation in the surf zone. In: Hansen, H., Larson, M. (Eds.), Proc. of Coastal Dynamics '01, Lund-Sweden, pp. $64-74$.
Short, A.D., Aagaard, T., 1993. Single and multi-bar beach change models. J. Coastal Res. SI 15, 141-157.

Stive, M.J.F., 1984. Energy dissipation in waves breaking on gentle slopes. Coast. Eng. 8, 99-127.

Svendsen, I.A., 1984. Wave heights and set-up in a surf zone. Coast. Eng. 8, 303-329.

Svendsen, I.A., Madsen, P.A., Buhr Hansen, J., 1978. Wave characteristics in the surf zone. Proc. 16th Coast. Eng. Conf., Hamburg, $520-539$.

Symonds, G., Huntley, D.A., Bowen, A.J., 1982. Two-dimensional surf beat: Long wave generation by a time-varying breakpoint. J. Geophys. Res. 87, 492-498.

Thornton, E.B., Guza, R.T., 1982. Energy saturation and phase speeds measured on a natural beach. J. Geophys. Res. 87, 9499-9508.

Thornton, E.B., Guza, R.T., 1983. Transformation of wave height distribution. J. Geophys. Res. 88, 5925-5938.

Wright, L.D., Guza, R.T., Short, A.D., 1982. Dynamics of a highenergy dissipative surf zone. Mar. Geol. 45, 41-62. 